\title{
Afastamento e retorno ao trabalho: relatos de servidores públicos municipais*
}

\section{Absence and returning to work: reports of municipal public workers}

\author{
Ana Carolina Toniolo ${ }^{1}$, Isabela Aparecida de Oliveira Lussi²
}

http://dx.doi.org/10.11606/issn.2238-6149.v27i2p123-130

Toniolo AC, Lussi IAO. Afastamento e retorno ao trabalho: relatos de servidores públicos municipais. Rev Ter Ocup Univ São Paulo. 2016 maio-ago.;27(2):123-30.

RESUMO: O objetivo do estudo foi verificar qual(is) suporte(s) trabalhadores afastados por transtornos mentais e do comportamento receberam no momento do afastamento do trabalho, mas, especialmente, no retorno às atividades, após receberem benefício auxílio-doença concedido pelo INSS. Participaram do estudo sete trabalhadores de uma Prefeitura Municipal do interior do estado de São Paulo, que conseguiram retornar às atividades de trabalho após serem afastados por 30 dias ou mais com diagnóstico primário de Transtornos Mentais e do Comportamento, no período de janeiro de 2008 a dezembro de 2012. A coleta de dados se deu por meio do preenchimento de um protocolo de informações pessoais, profissionais e referentes ao processo de afastamento e retorno ao trabalho e da aplicação de uma entrevista semiestruturada. Para análise dos dados, foi utilizada a técnica de Análise Temática. Os resultados mostraram que os participantes identificam família, amigos, profissionais da saúde e da prefeitura e eles mesmos como suporte durante o afastamento e no retorno às atividades de trabalho.

DESCRITORES: Trabalho; Retorno ao trabalho; Transtornos mentais; Saúde do trabalhador.
Toniolo AC, Lussi IAO. Absence and returning to work: reports of municipal public workers. Rev Ter Ocup Univ São Paulo. 2016 May-Aug.;27(2):123-30.

\begin{abstract}
The aim of this study was to determine which one support workers away from mental and behavioral disorders received at time of absence from work, but especially in returning activities after receiving sickness benefit granted by the INSS. Participants were seven employees of a municipal government in the state of São Paulo, which got to return to work activities after being away for 30 days or more with a primary diagnosis of Mental and Behavioral Disorders, from January 2008 to December, 2012. Data collection was done through filling in a protocol for personal, professional and related to the removal and return to work and the application of a semi-structured interview. For data analysis the technique of thematic analysis was used. The results showed that the participants identified family, friends, health and from the municipal government professionals and themselves as support during removal and return to work activities.
\end{abstract}

KEYWORDS: Work; Return to work; Mental disorders; Occupational health.

\footnotetext{
*Este trabalho é parte dos resultados de uma dissertação de mestrado defendida em 2014, no Programa de Pós-Graduação em Terapia Ocupacional da Universidade Federal de São Carlos - PPGTO/ UFSCar, intitulada "Retorno ao trabalho e transtornos mentais e do comportamento: um estudo com servidores públicos municipais".

1. Terapeuta Ocupacional (UFSCar - 2010). Mestre em Terapia Ocupacional (PPGTO/UFSCar - 2014). Terapeuta Ocupacional da Prefeitura Municipal de Piracicaba - SP, desde julho de 2014. E-mail: anatoniolo@gmail.com

2. Professora Adjunta da Universidade Federal de São Carlos - UFSCar, vinculada ao Departamento de Terapia Ocupacional, ao Programa de Pós-Graduação em Terapia Ocupacional e ao Núcleo Multidisciplinar e Integrado de Estudos, Formação e Intervenção em Economia Solidária (NuMI-EcoSol) de São Carlos-UFSCar.

Fonte de Financiamento: CAPES - Coordenação de Aperfeiçoamento de Pessoal de Ensino Superior.

Endereço para correspondência: Departamento de Terapia Ocupacional, Rod. Washington Luís, km 235, São Carlos - SP, Brasil; CEP: 13565-905. E-mail: bellussi@ufscar.br, telefone para contato: (16)33066627, (16)33518342, (16)33518701.
} 


\section{INTRODUÇÃO}

Portaria 1.823 do Ministério da Saúde,
de 23 de agosto de $2012^{1}$, que institui a
Política Nacional de Saúde do Trabalhador e da Trabalhadora no Brasil, afirma que o trabalho é um dos determinantes do processo saúde-doença e reconhece como complexa a relação trabalho-saúde. Ghisleni e Merlo² sugerem que afecções que expressam sofrimentos advindos da relação trabalhador-trabalho devem ser consideradas um problema de saúde pública.

Entre os comprometimentos causados pelo trabalho na saúde dos trabalhadores estão os relacionados à saúde mental. Os Transtornos Mentais e do Comportamento (CID F00 ao F99 do Código Internacional de Doenças - CID10) ocupam o terceiro lugar em número de auxílios-doença concedidos (previdenciários e acidentários) pelo Instituto Nacional do Seguro Social - INSS ${ }^{3}$. Avaliar e relacionar o adoecimento mental ao trabalho é um processo complexo e, nesse contexto, observa-se que existe um número crescente de pessoas que não conseguem permanecer trabalhando nas empresas e são isoladas ou demitidas por apresentarem transtornos psíquicos ${ }^{4}$.

Os trabalhadores que adoeceram e foram afastados das atividades laborais, encontram obstáculos que dificultam o processo de retorno ao trabalho ${ }^{5}$. A constatação das dificuldades existentes nos processos de retorno ao trabalho evidencia um problema de saúde pública, porém, ao longo das últimas décadas, o retorno ao trabalho tem sido a etapa menos abordada na atenção à saúde do trabalhador ${ }^{6}$.

Na questão sobre a incapacidade para o trabalho, a resposta pública se configura por meio da prática da reabilitação profissional ${ }^{7}$. Apesar dos transtornos mentais e do comportamento marcarem presença significativa nos bancos de dados da Previdência Social, estes casos são pouco contemplados pelo Programa de Reabilitação Profissional; a atenção aos mesmos é desenvolvida nos Centros de Atenção Psicossocial (CAPS) da Rede do Sistema Único de Saúde (SUS) ${ }^{7}$.

Atualmente, é previsto que o Sistema Único de Saúde (SUS) integre todas as ações que antes estiveram dispersas por vários níveis de atenção e esferas do governo. Porém, algumas ações ainda se concentram em outros setores, como aquelas relacionadas à vigilância do trabalho (Ministério do Trabalho) ou à reabilitação profissional $^{5}$. Ao tratar separadamente aspectos que são indissociáveis, fica evidente a precariedade que o poder público trata questões relativas à saúde do trabalhador ${ }^{8}$.
Para Lancman et al. ${ }^{5}$, esse quadro revela uma política que não define responsabilidades em relação à manutenção ou recolocação do trabalhador no mercado de trabalho, resultando em modelos pouco resolutivos e que geram um "jogo de empurra-empurra" (p.139) entre órgão público e empresas. Ao final, é penalizado o sujeito mais vulnerável de todo o processo: o trabalhador.

Este estudo teve como objetivo identificar qual(is) suporte(s) trabalhadores afastados por transtornos mentais e do comportamento receberam no momento do afastamento do trabalho, mas, especialmente, no retorno às atividades, após receberem benefício auxílio-doença concedido (por incapacidade) pelo INSS. Está vinculado à pesquisa desenvolvida no Programa de Pós-Graduação em Terapia Ocupacional da Universidade Federal de São Carlos, intitulada "Retorno ao trabalho e transtornos mentais e do comportamento: um estudo com servidores públicos municipais".

\section{PROCEDIMENTOS DE PESQUISA}

O campo de estudo se refere à Prefeitura Municipal de uma cidade do interior do Estado de São Paulo, na qual trabalham cerca de 4.500 servidores.

Participaram sete trabalhadores, que conseguiram retornar às atividades de trabalho após serem afastados por 30 dias ou mais com diagnóstico primário de Transtornos Mentais e do Comportamento (CID F do CID-10), no período de janeiro de 2008 a dezembro de 2012 .

Trata-se de uma pesquisa transversal descritiva, que adotou abordagem qualitativa por ser adequada para o alcance dos objetivos traçados. A coleta de dados se deu por meio do preenchimento de um Protocolo de informações pessoais, profissionais e referentes ao processo de afastamento e retorno ao trabalho e da aplicação de uma entrevista semiestruturada que versou sobre questões relacionadas ao significado do trabalho, aos fatores determinantes do afastamento e do retorno ao trabalho e aos apoios e fontes de suporte recebidos pelos trabalhadores durante o afastamento e no retorno ao trabalho. Os instrumentos foram elaborados pelas pesquisadoras a partir da revisão de literatura da área e em construção coletiva junto a profissionais que atuam no campo da saúde do trabalhador.

$\mathrm{Na}$ primeira etapa do estudo, por meio de envio de Ofício à Secretaria Municipal de Administração e Gestão de Pessoal da Prefeitura Municipal em questão, foram obtidos os números de benefícios auxílio-doença concedidos, no período de janeiro de 2008 a dezembro de 2012. Foram registrados 17.594 afastamentos, que 
tinham como diagnóstico primário diferentes tipos de CID. A partir desta lista, foram filtrados os afastamentos concedidos por Transtornos Mentais e do Comportamento (Grupo F do CID-10) e obteve-se um número de 1.239 afastamentos.

Em seguida foram extraídos os sujeitos que ficaram afastados do trabalho por 30 dias ou mais, o que levou à construção de uma lista com 23 potenciais participantes.

Para se configurarem como participantes, os trabalhadores deveriam responder aos seguintes critérios de inclusão:

- Terem sido afastados do trabalho por Transtornos Mentais e do Comportamento, no período de janeiro de 2008 a dezembro de 2012;

- Terem permanecido afastados por 30 dias ou mais;

- Conseguiram retornar às atividades de trabalho, após afastamento.

Foram realizados contatos com cada pessoa por meio de ligações telefônicas, a fim de fazer o convite e esclarecer dúvidas sobre a participação na pesquisa.

As 21 pessoas da lista (excetuando-se duas que participaram do estudo piloto) foram contatadas por meio de ligação telefônica e as entrevistas eram agendadas na medida em que os participantes eram localizados e aceitavam participar do estudo. Sete aceitaram participar da entrevista e 14 não aceitaram, por razões particulares.

As entrevistas foram realizadas no período de janeiro a março de 2013, em locais escolhidos pelos participantes. Cinco escolheram ser entrevistadas em casa e dois no ambiente de trabalho.

Para a análise dos dados, foi utilizada a técnica de Análise Temática, proposta por Bardin ${ }^{11}$. Essa técnica de Análise do Conteúdo tem foco no significado que emerge da análise de um texto e é rápida e eficaz para se aplicar a discursos diretos e simples na investigação dos temas ${ }^{11}$. As entrevistas foram transcritas na íntegra pela pesquisadora. Em seguida, foi feita a padronização das transcrições de modo que todas as entrevistas fossem ordenadas pelos dados de identificação.

$\mathrm{Na}$ sequência, foi feita a leitura exaustiva das entrevistas a fim de obter a apreensão global das mesmas. Buscou-se a identificação das unidades de significação ou dos temas significativos, tendo como pano de fundo os objetivos pré-estabelecidos. Após essa identificação, foi realizada a agregação dos temas elaborando-se, assim, as categorias representativas.

Os dados oriundos do Protocolo de informações pessoais, profissionais e referentes ao processo de afastamento e retorno ao trabalho tiveram análise descritiva.

\section{Aspectos éticos}

Nessa pesquisa, os procedimentos adotados obedeceram aos preceitos éticos recomendados em pesquisas envolvendo seres humanos. Os trabalhadores que aceitaram participar foram solicitados a assinarem o Termo de Consentimento Livre e Esclarecido (TCLE). O estudo foi aprovado pelo Comitê de Ética em Pesquisa em Seres Humanos da Universidade Federal de São Carlos, em 11/12/2012, com número de parecer: 166.976 .

\section{RESULTADOS}

\section{Caracterização dos trabalhadores}

Os dados obtidos por meio da aplicação do Protocolo de informações pessoais, profissionais e referentes ao processo de afastamento e retorno ao trabalho, permitiram a caracterização dos participantes do estudo.

Os participantes são trabalhadores da Prefeitura Municipal de uma cidade do interior do Estado de São Paulo que, no período de janeiro de 2008 a dezembro de 2012, foram afastados do trabalho com diagnóstico primário de Transtornos Mentais e do Comportamento por 30 dias ou mais e, após afastamento, conseguiram retornar às atividades de trabalho.

Dentre os participantes, cinco são do sexo feminino e dois do sexo masculino. A idade destes participantes variou entre 29 e 53 anos. Quanto ao estado civil, quatro são casados, uma é solteira e duas declararam "união estável". Sobre a formação escolar, três possuem Ensino Médio Completo, outros três participantes declararam Ensino Superior Incompleto e uma participante relata ter Ensino Superior Completo e Pós-Graduação. Para melhor visualização destes dados, elaborou-se o Quadro 1. A fim de manter a identidade dos sujeitos preservada, presou-se por manter suas funções em sigilo e apenas generalizá-las, para que não possam ser identificados. 
Quadro 1 - Caracterização dos participantes da pesquisa

\begin{tabular}{|c|l|l|l|l|l|}
\hline Participante & Sexo & Idade & Estado Civil & Escolaridade & Profissão \\
\hline S1 & Fem & 46 anos & União estável & Ensino médio completo & Profissional da Saúde \\
\hline S2 & Fem & 53 anos & União estável & Superior incompleto & Auxiliar administrativo \\
\hline S4 & Fem & 29 anos & Casada & Ensino médio completo & Profissional da Saúde \\
\hline S5 & Masc & 46 anos & Casado & $\begin{array}{l}\text { Superior completo e } \\
\text { Pós-graduação }\end{array}$ & Profissional da Educação \\
\hline S6 & Fem & 45 anos & Solteira & Superior incompleto & $\begin{array}{l}\text { Profissional da Construção completo } \\
\text { Civil }\end{array}$ \\
\hline S7 & Masc & 33 anos & Casado & Superior incompleto & $\begin{array}{l}\text { Funcionário da Segurança } \\
\text { Municipal }\end{array}$ \\
\hline
\end{tabular}

Fonte: elaboração nossa

Além desses dados, identificou-se que apenas um dos participantes declarou ter passado por processo de Readaptação de Função (S4). Mas é possível notar que outros participantes passaram a exercer outras atividades após retorno ao trabalho, mesmo sem terem participado de processo de Readaptação Funcional (S1, S2 e S6), como ilustra o Quadro 2.
Quanto aos diagnósticos primários de afastamento e período em que os trabalhadores se mantiveram longe das atividades de trabalho (Quadro 3), encontrou-se a seguinte diversidade:

Nota-se a prevalência dos Transtornos de humor (F31; F32; F32.3; F33.3), seguidos dos Transtornos neuróticos, transtornos relacionados ao stress e transtornos somatoformes (F41 e F48).

Quadro 2 - Participantes que passaram por Processo de Readaptação de Função

\begin{tabular}{|c|l|c|l|l|l|}
\hline Participante & Função & $\begin{array}{l}\text { Passou por } \\
\text { Readaptação de } \\
\text { Função? }\end{array}$ & $\begin{array}{l}\text { Atividade que } \\
\text { desempenhava } \\
\text { quando adoeceu }\end{array}$ & $\begin{array}{l}\text { Atividade que desem- } \\
\text { penhou no retorno ao } \\
\text { trabalho }\end{array}$ & Atividade atual \\
\hline S1 & $\begin{array}{l}\text { Profissional da } \\
\text { Saúde }\end{array}$ & Profissional da Saúde & Profissional da Saúde & $\begin{array}{l}\text { Auxiliar em } \\
\text { departamento de } \\
\text { compras da Prefeitura }\end{array}$ \\
\hline S2 & $\begin{array}{l}\text { Auxiliar } \\
\text { administrativo }\end{array}$ & Não & Recepcionista & Recepcionista & Recepcionista \\
\hline S3 & $\begin{array}{l}\text { Profissional da } \\
\text { Saúde }\end{array}$ & Sim & Profissional da Educação & $\begin{array}{l}\text { Profissional da } \\
\text { Educação }\end{array}$ & Auxiliar administrativo \\
\hline S4 & $\begin{array}{l}\text { Profissional da } \\
\text { Educação }\end{array}$ & $\begin{array}{l}\text { Não } \\
\text { Construção Civil }\end{array}$ & Serviços gerais & $\begin{array}{l}\text { Profissional da } \\
\text { Construção Civil }\end{array}$ & $\begin{array}{l}\text { Profissional da } \\
\text { Construção Civil }\end{array}$ \\
\hline S5 & $\begin{array}{l}\text { Profissional da } \\
\text { Educação }\end{array}$ & Não & Assessor administrativo & $\begin{array}{l}\text { Assessor } \\
\text { administrativo }\end{array}$ & Profissional da Educação \\
\hline S7 & $\begin{array}{l}\text { Funcionário } \\
\text { da Segurança } \\
\text { Municipal }\end{array}$ & Não & $\begin{array}{l}\text { Funcionário da } \\
\text { Segurança Municipal }\end{array}$ & $\begin{array}{l}\text { Funcionário da } \\
\text { Segurança Municipal }\end{array}$ & $\begin{array}{l}\text { Funcionáde } \\
\text { (mudançá de posto de } \\
\text { trabalho) }\end{array}$ \\
\hline
\end{tabular}

Fonte: elaboração nossa 
Toniolo AC, Lussi IAO. Afastamento e retorno ao trabalho. Rev Ter Ocup Univ São Paulo. 2016 maio/ago.;27(2):123-30.

Quadro 3 - Diagnósticos primários dos participantes da pesquisa e período de afastamento

\begin{tabular}{|c|l|l|}
\hline Participante & Período de Afastamento & \multicolumn{1}{c|}{ Diagnóstico Primário } \\
\hline S1 & 60 dias & F32.3 - Episódio depressivo grave com sintomas psicóticos \\
\hline S2 & 30 dias & F31 - Transtorno Afetivo Bipolar \\
\hline S3 & 30 dias & F48 - Outros transtornos neuróticos \\
\hline S4 & 90 dias & F41 - Outros transtornos ansiosos \\
\hline S5 & 30 dias & F32 - Episódios depressivos \\
\hline S6 & 60 dias & F31 - Transtorno Afetivo Bipolar \\
\hline S7 & 30 dias & $\begin{array}{l}\text { F33.3 - Transtorno depressivo recorrente, episódio atual grave com sintomas } \\
\text { psicóticos }\end{array}$ \\
\hline
\end{tabular}

Fonte: elaboração nossa

\section{Análise temática}

A análise das entrevistas semiestruturadas permitiu a identificação das seguintes categorias temáticas:

- Os sentidos do trabalho para os participantes;

- O trabalhador, o médico do trabalho e o perito do INSS: relações favorecedoras ou desfavorecedores para o retorno ao trabalho?;

- Rede, suportes, apoios sociais no processo de retorno ao trabalho;

- Sobre organizações, relações e condições de trabalho.

Neste artigo são apresentados os resultados da categoria "Redes, suportes, apoios sociais no processo de retorno ao trabalho".

Os relatos dos participantes mostram a identificação de suportes ou apoio que receberam durante o afastamento, mas, principalmente, no momento do retorno às atividades laborais. Pode-se observar que tais suportes são de tipos diversos e estão relacionados à família e amigos, à Prefeitura e profissionais da saúde, ou ao próprio participante do estudo, como serão apresentados a seguir.

Os participantes foram unânimes em identificar a família como fonte de suporte no momento do retorno ao trabalho. A maioria define o cônjuge como principal suporte, que oferece apoio não só prático, mas, também, afetivo, como ilustram os relatos a seguir:

"A minha família. Meu marido, minha mãe, minhas irmãs. A mãe ainda que a gente segura um pouco por causa da idade" (S1).

“Eu tenho só meu irmão (...). Mas de outras pessoas, não tive apoio nenhum. É... Na verdade, são meus parentes, principalmente, esse meu irmão, que sofre. E minhas tias que falam 'não, vem pra cá, fica em casa' (...). E eu tenho a sorte de ter um marido compreensivo (...) que compreende, que reconhece que é dificil" (S2).

“(...) principalmente meu marido, em casa” (S4).

"Eu percebi que tinha alguém que gostava de mim, tinha e tem até hoje, e eu também preciso gostar de mim. Não adianta nada a R. [esposa] gostar de mim e eu não gostar de mim” (S5).

"Aqui em casa, tive apoio do meu namorado..." (S6).

“Ah... É mais a família mesmo, minha mulher, apesar que ela trabalha no mesmo serviço e também estava sofrendo as mesmas coisas. Então, é bem complicado" (S7).

Além da família, um dos participantes referiu ter recebido apoio de colegas de trabalho. O trabalhador aponta que esses amigos, notaram e ajudaram a identificar que ele estava adoecido e precisava de ajuda.

"Tudo foi meu esposo que correu atrás. Lógico que a gente tem uns amigos que trabalham na área da saúde que falaram 'olha, seria bom se você fizesse um tratamento com um terapeuta, com psicólogo, com psiquiatra"," (S3).

Além do amparo recebido por parentes e amigos, alguns participantes tomaram como suporte o apoio de médicos, psicólogos e outros profissionais da saúde. Os relatos a seguir ilustram como o apoio de profissionais é significativo na vida dos trabalhadores.

“(...) o médico, psiquiatra, que acho que é importante. Ele diz que é melhor eu ter horário pra sair de casa, vou me arrumar, vou voltar" (S2). 
"Hoje, a gente vê, eu falo que se não fosse a terapia semanal, eu não estaria nem conversando com você (...). Só quem consegue me entender é o psiquiatra, o psicólogo e a terapeuta [ocupacional]” (S3).

“(...) tive apoio (...) do médico; o médico conversava comigo no [site e serviço de rede social] à noite. Fui muito privilegiada. Então, tudo isso colaborou, muito!’'(S6).

Um dos participantes permaneceu internado durante o período de afastamento em uma clínica de recuperação. Este participante, conta que recebeu apoio dos profissionais da clínica não só durante a internação, mas pode contar até hoje com o suporte da equipe:

“(...) eles disseram pra mim 'o que você precisar, você procura a gente'. Essa semana mesmo, quando aconteceu um incidente com meu filho, eu liguei pro coordenador da clínica e conversei bastante com ele e ele falou 'quando precisar, liga; quando tiver alguma dúvida, qualquer coisa, quando precisar de um amigo pra conversar, liga pra mim'. Conversei bastante com ele" (S5).

Este participante frequenta as reuniões de um Grupo de Apoio Terapêutico da Prefeitura desde antes do afastamento do trabalho e possui um vínculo maior com dois profissionais do SESMT (Serviço Especializado em Engenharia de Segurança em Medicina do Trabalho) da Prefeitura, que coordenam o grupo. O servidor relata que se sente amparado por esses profissionais:

"E na Prefeitura é a mesma coisa. Se eu precisar de alguma coisa eu ligo e converso com [profissional do SESMT]. Então, tenho suporte sim, é só eu procurar" (S5).

Quanto ao suporte dado pelo SESMT da Prefeitura, a maioria dos trabalhadores relata passar apenas por uma conversa com o Médico do Trabalho, quando o prazo do afastamento acaba e chega a data de retornar às atividades. Depois que retornam ao trabalho, os trabalhadores contam que não há mais contato:

“Assim... Diretamente foi só aquele dia da entrevista para retorno, para passar pelo médico; passei, conversei bastante com [profissionais do SESMT]. Mas depois disso não teve mais nada. Eu que vou lá (...), eu que procuro. Eles não me procuram, não ficam ligando; só se falam com alguém da chefia. Mas eu quem procuro" (S5).
Se destaca nas entrevistas o fato que a maioria dos participantes se vê como principal fonte de suporte na recuperação e tomada de decisão sobre o retorno ao trabalho. Os participantes se veem como pessoas ativas e principais atores na iniciativa de recuperar-se e conseguir voltar às atividades de trabalho, como ilustram os relatos a seguir:

“(...) eu tinha que lutar contra aquilo que eu estava sentido, então, era a busca consigo mesmo, foi o que eu procurei fazer: 'olha isso vai passar', começar a ter outro pensamento (...). E era assim: 'meu Deus tira esse mau pensamento de mim, tira essa angústia que estou sentindo,"' (S1).

Tanto é que eu voltei antes do tempo (...). Mas eu quero voltar, eu quero trabalhar, eu não gosto de ficar parada. Então, é porque eu gosto do que eu faço. Então, é isso que me faz querer voltar, é o gostar do que eu faço" (S6).

Os relatos possibilitam perceber que o trabalho assume uma posição ligada à questão de identidade dos sujeitos.

\section{DISCUSSÃO}

Em relação aos diagnósticos apresentados pelos participantes, nenhum deles é reconhecido como relacionado ao trabalho pelos Ministérios da Saúde e da Previdência Social. Alguns autores consideram que os transtornos mentais representam uma das mais complexas situações a serem periciadas ${ }^{13,14}$. Um estudo comparativo em duas Agências da Previdência Social da Gerência Executiva de Juiz de Fora (MG), discute questões sobre a prevalência de quadros ansiosos e depressivos na concessão de benefícios auxílio-doença. Os autores apontam que, para além das dificuldades em se diagnosticar quadros psiquiátricos, pode existir uma insuficiência de treinamento dos peritos médicos para a avaliação de trabalhadores com transtornos mentais e do comportamento. O perito médico, a depender de sua formação poderá valorizar certos sintomas que o segurado relata. A consequência disso é o registro frequente de determinados diagnósticos ${ }^{15}$.

Os resultados do estudo apontaram a família como fonte de suporte para os trabalhadores no momento do retorno ao trabalho. Esses resultados condizem com a literatura que aponta que a família representa um elemento decisivo da constituição de uma proteção aproximada do indivíduo ${ }^{16,17}$. 
Ao se identificarem como principal fonte de suporte na recuperação e tomada de decisão sobre o retorno ao trabalho, os trabalhadores evidenciam que o trabalho assume uma posição ligada à questão de identidade.

As questões de identidade estão atreladas à centralidade do trabalho na vida das pessoas que, como afirma Castel $^{18}$, é o elemento principal do eixo das relações sociais e da cidadania. Representada não apenas pelo exercício de um trabalho assalariado, mas na fundamentação da dignidade social, a força de trabalho permite que o indivíduo construa ações efetivas de produção na sociedade ${ }^{18}$.

Os participantes também identificaram os colegas de trabalho e os profissionais da saúde como fontes suporte no processo de afastamento e retorno ao trabalho, o que demarca a existência de uma rede social pessoal.

Para Sluzki ${ }^{19}$, apoios sociais relacionais são a rede pessoal e social de um indivíduo e não se resumem à família nuclear ou extensa, mas inclui todos os vínculos interpessoais do sujeito: família, amigos, colegas de trabalho ou estudo, relações de inserção na comunidade, de serviços e de práticas sociais. O contexto cultural, político, histórico, econômico, de meio ambiente, de existência ou não de serviços públicos, compõem o universo relacional do indivíduo. Sendo assim, a rede social pessoal nada mais é do que a "soma de todas as relações que um indivíduo percebe como significativas

\section{REFERÊNCIAS}

1. Brasil. Portaria $n^{0} 1.823$, de 23 de agosto de 2012. Institui a Política Nacional de Saúde do Trabalhador e da Trabalhadora. Diário Oficial da União, Brasília, DF, 23 ago. 2012.

2. Ghisleni AP, Merlo ARC. Trabalhador contemporâneo e patologias por hipersolicitação. Psicol Reflexão Crít. 2005;18(2):171-6.DOI: 10.1590/S0102-79722005000200004.

3. Jardim S. Depressão e trabalho: ruptura de laço social. Rev Bras Saúde Ocup. 2011;36(123):84-92. DOI: 10.1590/ S0303-76572011000100008.

4. Seligmann-Silva, E, Bernardo, MH, Maeno, M, Kato, M. O mundo contemporâneo do trabalho e a saúde mental do trabalhador. Rev Bras Saude Ocup. 2010;35(122):187-91. DOI: $10.1590 / \mathrm{S} 0303-76572010000200002$.

5. Lancman S, Dalton MT, Barros J, Gonçalves R, Jardim T. Processos de retorno e permanência no trabalho: elementos estruturantes para a construção de um modelo de ação. In: Simonelli AP, Rodrigues DS, organizadores. Saúde e trabalho ou define como diferenciadas da massa anônima da sociedade" (p.41) $)^{19}$.

\section{CONCLUSÕES}

Este estudo teve como objetivo identificar qual(is) suporte(s) trabalhadores afastados por transtornos mentais e do comportamento receberam no momento do afastamento do trabalho, mas, especialmente, no retorno às atividades, após receberem benefício auxílio-doença concedido pelo INSS.

Os resultados da pesquisa mostraram que os participantes foram unânimes em considerar suas famílias como principal fonte de suporte no processo de retorno às atividades de trabalho. Apesar de identificarem os amigos, a Prefeitura, os profissionais da saúde e eles próprios também como suporte neste processo, nem todos classificaram esses fatores da mesma forma que a família, que foi eleita como suporte para todos os participantes.

Pela limitação da amostra, os resultados da presente pesquisa não podem ser generalizados, porém, suscitam questões gerais, principalmente quanto ao suporte dos trabalhadores no processo de afastamento e retorno ao trabalho. Espera-se que este estudo contribua para a produção de conhecimento e discussões sobre a atuação do terapeuta ocupacional, bem como de outros profissionais, na área da Saúde do Trabalhador.

em debate: velhas questões, novas perspectivas. Brasília: Paralelo 15; 2013.

6. Maeno M, Takahashi MABC, Lima MAG. Reabilitação profissional como política de inclusão social. Acta Fisiátr. 2009;16:53-8.

7. Takahashi MABC, Kato M, Leite RA. O. Incapacidade, reabilitação profissional e saúde do trabalhador: velhas questões, novas abordagens. Rev Bras Saúde Ocup. 2010;35(121):7-9. DOI: 10.1590/S030376572010000100002 .

8. Simonelli AP, Camarotto JA, Bravo ES, Vilela RAG. Proposta de articulação entre abordagens metodológicas para melhoria do processo de reabilitação profissional. Rev Bras Saúde Ocup. 2010;35(121):64-73. DOI: 10.1590/S030376572010000100008 .

9. Minayo MCS, Sanches O. Quantitativo-qualitativo: oposição ou complementaridade? Cad Saúde Pública. 1993;9(3):23962. DOI: 10.1590/S0102-311X1993000300002. 
10. Sampieri RH, Collado CF, Lucio PB. Metodologia de pesquisa. São Paulo: McGraw Hill; 2006.

11. Bardin L. Análise de conteúdo. Lisboa: Edições 70; 2008.

12. Conselho Nacional de Ética em Pesquisa. Resolução 196/1996. 2012.

13. Melo MPP, Assunção AA. A decisão pericial no âmbito da previdência social. Physis Rev Saúde Coletiva. 2003;13(2):343-65. DOI: 10.1590/S010373312003000200007.

14. Gonzaga P. Perícia médica da previdência social. 4a ed. São Paulo: LTr; 2006.

15. Siano AK, Ribeiro LC, Ribeiro MS. Análise comparativa do registro médico-pericial do diagnóstico de transtornos mentais de segurados do Instituto Nacional do Seguro Social requerentes de auxílio-doença. J Bras Psiquiatr. 2010;59(2):131-8. DOI: 10.1590/S0047-20852010000200009.

16. Castel R. A dinâmica dos processos de marginalização: da vulnerabilidade à "desfiliação". Cad CRH. 1997;26/27:19-40.

17. Castel R. Da indigência à exclusão, a desfiliação: precariedade do trabalho e vulnerabilidade relacional. In: Lancetti A. Saúde loucura 4: grupos coletivos. São Paulo: Hucitec; 1994.

18. Castel R. As metamorfoses da questão social: uma crônica do salário. São Paulo: Vozes; 2012.

19. Sluzki CE. A rede social na prática sistêmica. São Paulo: Casa do Psicólogo; 1997.

Recebido em: 30.10 .15

Aceito em: 13.01.16 